Egypt. Acad. J. Biolog. Sci., 5(2): 99-107 (2013)

Email: egyptianacademic@yahoo.com

Received: 25 / 4 /2013
C. Physiology \& Molecular Biology

ISSN: 2090-0767

www.eajbs.eg.net

\title{
Molecular genetic identification of two bracon species based on RAPD-PCR and 16S rRNA genes
}

\author{
Reda F.A. Bakr ${ }^{1}$, Mohamed Ahmed Gesraha², Noha Awny Mohamed Guneidy ${ }^{1}$, \\ Nagy Abd Elatief Farag ${ }^{2}$, Amany Ramadan Ebeid ${ }^{2}$, Hoda Hassan Ali Elbehery ${ }^{2}$ \\ and Mohamed Abou-Ellail ${ }^{3}$ \\ 1- Faculty of Science Ain Shams University Cairo, Egypt. \\ 2- Pests and Plant Protection Dept., Agricultural and Biological Division, National \\ Research Center, Dokki, Cairo, Egypt. \\ 3- Department of Cytology and Genetics, Genetic Engineering and Biotechnology \\ Division, National Research Centre, Cairo, Egypt \\ Corresponding Email: abou_ellail@yahoo.com
}

\begin{abstract}
Random amplified polymorphic DNA (RAPD)-PCR genomic fingerprinting and partial sequencing of the $16 \mathrm{~S}$ rRNA gene were evaluated on two insects collected from the Egyptian field which could belong to B. hebetor and B. brevicornis to investigate their genetic relatedness and to establish the value of techniques for their identification. Nearly identical RAPD-PCR profiles and identical $467 \mathrm{bp}$ fragments of the 16S rRNA genes indicated many of genetic diversity between the two insects under study. The low levels of similarity $(78.21 \%$ in the partial $16 \mathrm{~S}$ rRNA genes and $86 \%$ in RAPD-PCR) appeared between the insects $B$. hebetor egypt and $B$. brevicornis egypt. However, 16S rRNA genes and RAPD-PCR provided an effective means of differentiating between members of the taxa. Moreover, a phylogenetic tree constructed from 16S rDNA sequences showed that $B$. hebetor egypt clustered with the B. hebetor with a degree of similarity $92 \%$, but B. brevicornis Egypt clustered in a separated group. However, RAPD-PCR and partial sequencing of the 16S rDNA analysis raises questions about the taxonomic positioning of the two insects isolated from the Egyptian environment.
\end{abstract}

Keywords: RAPD-PCR and 16S rRNA genes - bracon species

\section{INTRODUCTION}

The identification and the use of correct parasitoids species is very important step in biological control programs to be released in the field. The identification of these parasitoids is difficult due to the most parasitoids are small, even minute, and evolving rapidly. Related species often have few or no known sufficiently invariant distinguishing morphological characters for reliable discrimination (Pungerl, 1986; Landry et al., 1993; Pinto et al., 1993; Demichelis \& Manino, 1998; Kimani-Njogu et al., 1998; Stouthamer et al., 1999; Barnay et al., 2001; Chang et al., 2001) and their identification at species level depends mainly on male genitalia. Failure or delay the definition of parasite affect the outcome of the control of pest where the success of biological control programs often depends on correct identification of natural enemies (DeBach and Rosen, 1991). Today's technology allows us to identify any living thing by using a single cell.

The classification of species based on morphological features has problems because morphological attributes could change by environment (Shouche and Patole, 2000). Many molecular techniques allow ecologists and biologists to determine the genetics array 
of a wide variety of closely related individuals (Wolf and Rijn, 1993). Among these techniques are DNA sequencing, restriction fragment length polymorphisms (RFLP), microsatellites analysis and random amplified polymorphic DNA (RAPD) (Mulcahy et al., 1993). Bracon spp is minute and indistinguishable morphologically, further, the environmental factors influence significantly its morphology and physiology. So, identification of the wasp is problematic and its systematic needs to be clarified (Pinto, 1998).

\section{MATERIALS AND METHODS Collection of samples:}

Two spices of Bracon insects presented in the Egyptian fields. They may be Bracon. hebetor and Bracon. brevicornis and they individuals were kept in liquid nitrogen until use.

\section{DNA extraction}

Total genomic DNA was extracted from fifteen bulk of the two individual species by using GeneJET ${ }^{\mathrm{TM}}$ Genomic DNA Purification kit (Fermentas). DNA samples were diluted by TE-buffer to final concentration of $50 \mathrm{ng} / \mu \mathrm{l}$ to be used in polymerase chain reaction (PCR) and stored at $-20^{\circ} \mathrm{C}$.

\section{PCR conditions and purification of PCR products}

For identification of two Bracon species, we used two categories, RAPDPCR and sequencing a part of mt16S rRNA genes. In RAPD-PCR method, twenty primers (table 1), obtained from Pharmacia Biotech. (Amersham Pharmacia Biotech UK Limited, Ebgland HP79 NA), were used in this experiment to identify the insects. Moreover, A partial of mitochondrial 16S rRNA gene (467 bp) was amplified and sequenced by using primers $16 \mathrm{sWb}$ sequence: 5'CACCTGTTTATCAAAAA-CAT-3';

16s.Sh sequence: 5'AGATTTTAAAAGTCGAA-CAG-3'

which were published by Heimpel et al., 1997.

Table 1: Twenty primer sequences used in identification of two Bracon species.

\begin{tabular}{|c|c|c|c|}
\hline Primer code & Sequences & Primer code & Sequences \\
\hline OPA-01 & CAGGCCCTTC & OP-B15 & GGAGGGTGTT \\
\hline OPA-02 & TGCCGAGCTG & OP-B16 & TTTGCCCGGA \\
\hline OPA-04 & AATCGGGCTG & OP-B18 & CCACAGCAGT \\
\hline OPA-05 & AGGGGTCTTG & OP-B20 & GGACCCTTAC \\
\hline OP-A09 & GGGTAACGCC & OP-C04 & CCGCATCTAC \\
\hline OPA-11 & CAATCGCCGT & OP-C05 & GATGACCGCC \\
\hline OPA-16 & AGCCAGCGAA & OP-C13 & AAGCCTCGTC \\
\hline OPA-18 & AGGTGACCGT & OP-C16 & CACACTCCAG \\
\hline OPA-19 & CAAACGTCGG & OP-C19 & GTTGCCAGCC \\
\hline OPA-20 & GACCAATGCC & OP-Q19 & CCCCCTATCA \\
\hline
\end{tabular}

PCR reactions were performed with GoTaq ${ }^{\circledR}$ Flexi DNA Polymerase kit (Promega), in a total volume of $25 \mu 1$ volume reaction mixture containing: 50 ng of total cellular DNA $(1 \mu 1$ DNA extraction), $100 \mu \mathrm{M}$ of primer $(1 \mu \mathrm{l}), 5 \mu \mathrm{l}$ of $5 \mathrm{X}$ green Taq DNA polymerase buffer, $5 \mathrm{U} / \mu 1$ of GoTaq DNA polymerase $(0.25 \mu \mathrm{l})$ (Promega), $10 \mathrm{mM}$ of each dNTP $(0.5 \mu \mathrm{l}), 25 \mathrm{mM} \mathrm{MgCl} 2(4 \mu \mathrm{L})$, up to $25 \mu \mathrm{l}$ by nuclease-free water. PCR was performed in a DNA thermocycler (Biometra, Germany). For RAPD-PCR program, samples were first heated at $94^{\circ} \mathrm{C}$ for $3 \mathrm{~min}$ and subjected to 35 cycles of the following cycle: 45 seconds at $94^{\circ} \mathrm{C}, 45$ seconds at $37^{\circ} \mathrm{C}, 1.5 \mathrm{~min}$ at $72^{\circ} \mathrm{C}$. A final step of $5 \mathrm{~min}$ at $72^{\circ} \mathrm{C}$ was always run. For a partial $16 \mathrm{~S}$ rDNA fragment amplification, $\mathrm{PCR}$ reaction mixture heated at $94^{\circ} \mathrm{C}$ for $3 \mathrm{~min}$ and subjected to 18 cycles of the following cycle: 45 seconds at $94^{\circ} \mathrm{C}, 45$ seconds at $44^{\circ} \mathrm{C}, 45$ seconds at $72^{\circ} \mathrm{C}$. A final step of 5 min at $72^{\circ} \mathrm{C}$. PCR reaction was tested on $1.8 \%$ agarose (Genetics) gel, $100 \mathrm{bp}$ 
DNA Ladder H3 RTU (Genetics) and $1 \mathrm{~Kb}$ DNA ladder (GeneRuler ${ }^{\mathrm{TM}}$ ) were used as the standard markers.

\section{Sequencing}

For sequencing of $16 \mathrm{~S}$ rDNA fragment ( $467 \mathrm{bp})$ we used sequencing unit which is equipped with a Tecan robot installed on a platform Genesis Workstation $\quad 150 \quad$ (capillary electrophoresis) and performs the reactions are then analyzed via the sequencer 3100 Genetic Analyser (Applied Biosystems). DNA fragments to be sequenced are prepared in a final reaction concentration $6 \mu \mathrm{l}$ content $30 \mathrm{ng}$ of PCR products and 5 pmol of the $16 \mathrm{sWb}$ or $16 \mathrm{~s}$.Sh primers. Sequence analysis was done with the Sequencher 3.0 software.

\section{Data analysis}

Data of reducible RAPD markers were scored "1" or "0" for each sample "1" was assigned for the presence of a band and " 0 " for its absence. These data were used in counting the number of total amplified markers in two Bracon spp. Moreover, pairwise comparisons of the two species, based on the presence or absence of unique and shared polymorphic products, were used to determine similarity coefficients, according to Jaccard (1908).

Three of partial sequences of $16 \mathrm{~S}$ rDNA were obtained from http://blast.ncbi.nlm.nih.gov/Blast.cgi, that in additional our two sequences were used for constructing the UPGMA phylogenetic tree. Phylogenetic analyses were conducted in MEGA4 (Tamura et al., 2007). Sequence alignments were carried out using the site http://www.ebi.ac.uk/Tools/msa/clustalw2/.

\section{RESULTS}

For estimation of genetic diversity of two species of insects presented in the Egyptian environment which could belong to Bracon hebetor and Bracon brevicornis we used RAPD-PCR and 16Ss rDNA sequences comparison.

RAPD-PCR is a powerful tool for the analysis of genetic diversity and was successfully used to compare genetic variation among the two species. RAPD produced by all 20 primers were used to evaluate the similarity between the studied insects as shown in Fig 1 and Table 2. The RAPD bands were ranged from 30 to $1500 \mathrm{bp}$. The twenty primers produced total 184 bands with average 9.2 per primer. The all primers generated a total of 137 monomorphic $(\sim 74 \%)$ and 47 polymorphic $(\sim 26 \%)$ bands in two insect under study.

The produced bands polymorphisms varied from primer to another. Among these primers, only 5 did not reveal any polymorphic bands and they produced the highly monoymorphic percentage $(100 \%)$, these are identified as B18, A05, Q16, C13 and A02. On the other hand, A16, A18, A19, B15, C04 and $\mathrm{C} 05$ showed highest percentage of polymorphism $(46 \%, 40 \%, 50 \%, 44 \%$, $50 \%$ and $56 \%$ ), respectively. Generally, the polymorphic percentage mean was 23.05\%. Moreover, we observed variation in number of bands presented by each primer. Whereas, the primer A09 amplified the highest number of bands (15 bands) with sizes ranged from 100 to $1330 \mathrm{bp}$. While the lowest number of bands (4 bands) were produced by the A02 primer. 


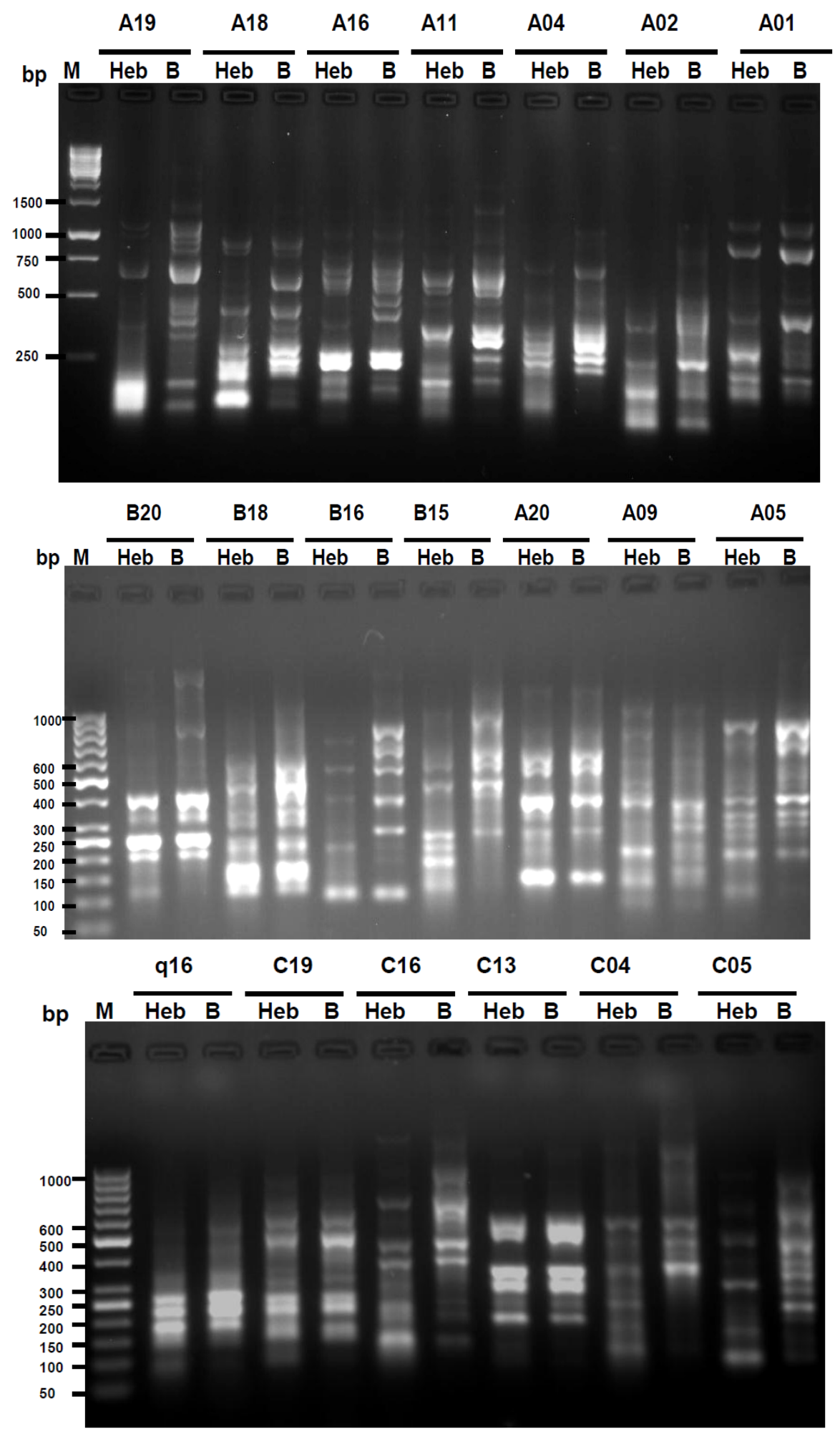

Fig. 1: RAPD amplified fragment produced by all 20 primers were used to evaluate the similarity and to compare genetic variation among the two insects. Heb: Bracon hebetor, B: Bracon brevicornis, M: Standard marker. 
Table 2: Polymorphisms and $\mathrm{F}$ value were revealed by the twenty primers that used for the identification of two Bracon species.

\begin{tabular}{|c|c|c|c|c|c|c|c|c|c|}
\hline \multirow[b]{3}{*}{ Primer } & \multirow{3}{*}{$\begin{array}{c}\text { Total } \\
\text { Amplification } \\
\text { products }\end{array}$} & \multirow{2}{*}{\multicolumn{2}{|c|}{ Total bands }} & \multirow[b]{3}{*}{$\begin{array}{l}\text { Monomorphic } \\
\text { bands }\end{array}$} & \multirow{2}{*}{\multicolumn{2}{|c|}{ Polymorphic bands }} & \multirow{3}{*}{$\begin{array}{l}\text { Polymorphic } \\
\text { bands } \\
\text { Size with bp }\end{array}$} & \multirow[b]{3}{*}{$\begin{array}{l}\text { Polymorphis } \\
\text { m percentage }\end{array}$} & \multirow{3}{*}{$\begin{array}{c}\mathrm{F} \\
\text { Value } \\
\%\end{array}$} \\
\hline & & & & & & & & & \\
\hline & & brevicornis & hebetor & & brevicornis & hebetor & & & \\
\hline $\mathrm{A} 01$ & 7 & 6 & 7 & 6 & 0 & 1 & 220 & $14 \%$ & $92 \%$ \\
\hline A02 & 4 & 4 & 4 & 4 & 0 & 0 & - & $0 \%$ & $100 \%$ \\
\hline A04 & 7 & 7 & 6 & 6 & 1 & 0 & 80 & $14 \%$ & $92 \%$ \\
\hline A 05 & 10 & 10 & 10 & 10 & 0 & 0 & & $0 \%$ & $100 \%$ \\
\hline A09 & 15 & 11 & 15 & 11 & 0 & 4 & $180-200-260-350$ & $27 \%$ & $85 \%$ \\
\hline A11 & 10 & 8 & 10 & 8 & 0 & 2 & $40-250$ & $20 \%$ & $89 \%$ \\
\hline A16 & 11 & 8 & 9 & 6 & 2 & 3 & $\begin{array}{c}110-140-370-400- \\
460 \\
\end{array}$ & $46 \%$ & $71 \%$ \\
\hline A 18 & 10 & 7 & 9 & 6 & 1 & 3 & $170-240-350-540$ & $40 \%$ & $75 \%$ \\
\hline A19 & 12 & 7 & 11 & 6 & 1 & 5 & $\begin{array}{c}280-330-360-380- \\
410-460\end{array}$ & $50 \%$ & $67 \%$ \\
\hline A20 & 8 & 8 & 7 & 7 & 1 & 0 & 220 & $13 \%$ & $93 \%$ \\
\hline B15 & 9 & 8 & 6 & 5 & 3 & 1 & $130-200-240-420$ & $44 \%$ & $71 \%$ \\
\hline B16 & 9 & 7 & 8 & 6 & 1 & 2 & $690-760-870$ & $33 \%$ & $80 \%$ \\
\hline B18 & 10 & 10 & 10 & 10 & 0 & 0 & - & $0 \%$ & $100 \%$ \\
\hline $\mathrm{B} 20$ & 7 & 7 & 6 & 6 & 1 & 0 & 120 & $14 \%$ & $92 \%$ \\
\hline $\mathrm{C} 04$ & 10 & 9 & 6 & 5 & 4 & 1 & $\begin{array}{c}120-180-230-260- \\
390\end{array}$ & $50 \%$ & $67 \%$ \\
\hline $\mathrm{C} 05$ & 11 & 7 & 9 & 5 & 2 & 4 & $\begin{array}{c}210-260-290-320- \\
410-440\end{array}$ & $56 \%$ & $63 \%$ \\
\hline $\mathrm{C} 13$ & 6 & 6 & 6 & 6 & 0 & 0 & - & $0 \%$ & $100 \%$ \\
\hline $\mathrm{C} 16$ & 10 & 9 & 9 & 8 & 1 & 1 & $300-370$ & $20 \%$ & $89 \%$ \\
\hline $\mathrm{C} 19$ & 10 & 9 & 9 & 8 & 1 & 1 & $360-390$ & $20 \%$ & $89 \%$ \\
\hline Q16 & 8 & 8 & 8 & 8 & 0 & 0 & - & $0 \%$ & $100 \%$ \\
\hline Total & 184 & 156 & 165 & 137 & 19 & 28 & & & \\
\hline Mean & & & & & & & & $23.05 \%$ & $86 \%$ \\
\hline
\end{tabular}

In order to study the similarity index between insects under study, we calculated the $\mathrm{F}$ value of each primer. The primers B18, A05, Q16, C13 and A02 show $100 \%$ identical similarity between the two species, otherwise lowest similarities $63 \%, 67 \%$ and $67 \%$ were detected by using primers C05, A19 and $\mathrm{C} 04$, respectively. In general, mean of the similarity detected by all primers was $86 \%$. RAPD results showed successfully the variation between the two insects.

For more clearly identification of the insects under study, we performed sequencing of mitochondrial 16S rDNA. $467 \mathrm{bp}$ fragment of the mitochondrial $16 \mathrm{~S}$ rRNA gene was successfully sequenced for the two insects (Fig. 2). 
BLAST analysis of $467 \mathrm{bp}$ from the two insects which could belong to Bracon hebetor Egypt and Bracon brevicornis Egypt (presented in Egypt, figure) showed significant homology with Bracon hebetor, Callibracon limbatus and Bracon phylacteophagus. However, we did not find sequences published to Bracon brevicornis in the NCBI-Gen Bank database. The phylogenetic UPGMA tree was carried out using MEGA 4 software (Fig. 4). The UPGMA tree was constructed based on the multiply aligned sequence data for five types of insects. The tree separates the genomes into two distinct groups, whereas the insects Bracon hebetor, Callibracon limbatus, Bracon phylacteophagus and Bracon hebetor Egypt were presented in one group but only the insect Bracon brevicornis Egypt was found in another group. 16S rRNA gene sequence informatics is one of the most attractive potential tools to provide genus and species identification and reclassification for the two insects under study.

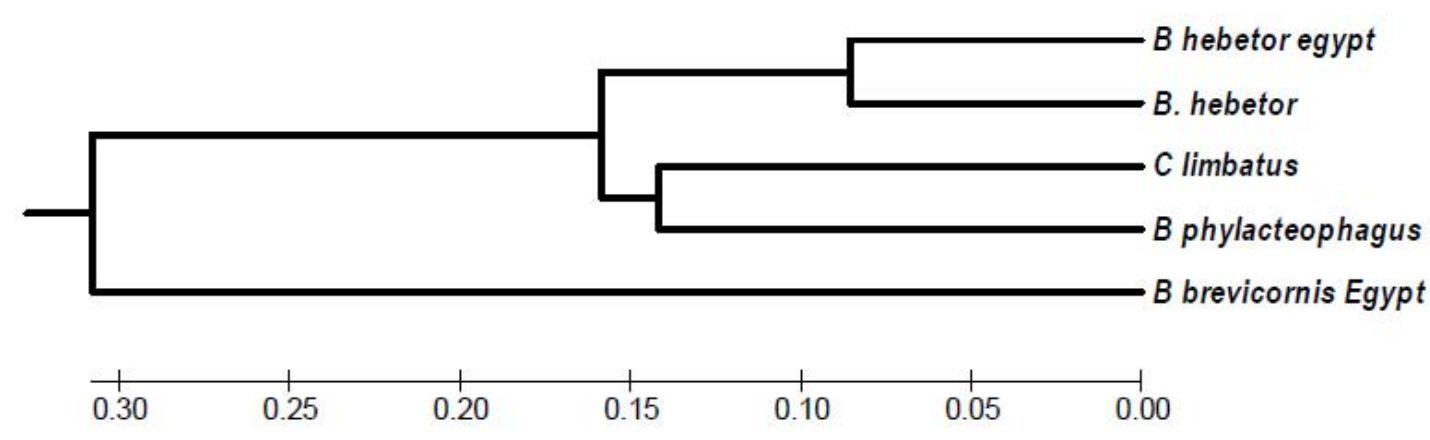

Fig. 4: The UPGMA tree was constructed based on the multiply aligned sequence data for two insects collected from Egyptian environment (Bracon hebetor Egypt and Bracon brevicornis Egypt) and other three insects sequences (Bracon hebetor, Callibracon limbatus and Bracon phylacteophagus published in the NCBI-GenBank database.

\section{DISCUSSION}

The molecular studies of Bracon species have produced interesting outcomes about the hidden relationships among species which could not be observed well by the phenotypic or behavioural studies (Aruggoda, et al., 2010). RAPD-PCR and 16S rDNA gene partial region were performed in order to infer the relationship of two insects.

The RAPD-PCR results were summarized in Table 2 and they revealed genetic variations between $B$. hebetor Egypt and B. brevicornis Egypt. As a matter of fact, the polymorphic percentage mean and the similarity were $\sim 23 \%$ and $86 \%$, respectively. These results suggested that $B$. hebetor Egypt and B. brevicornis Egypt have a common ancestor but this percentage of polymorphism could make us to think more in their taxonomy. This difference between the two insects could due to the natural environment and it is in agreement of Jain et al. 2010 who reviewed the importance to study the insects' ecology to understand their evolution and diversification, and their influence on the functional and trophic links between different components of associated habits. Moreover, The RAPD markers technique has been reported to be an efficient tool to discriminate genetically isolated species and to verify the existence of spices that presented as a result of genetic drift or natural selection (Fuchs et al., 1998). So the RAPD marker is useful in taxonomic and classification studies (Gala, 2009). 
The partial $16 \mathrm{~S}$ rDNA sequences uses in taxonomic studies (Hebert et al., 2003), has been applied mostly to known species. This region presents near the 3' end of the mitochondrial 16S rRNA gene and these sequences are adequate for species discrimination in various arthropod taxa (reviewed by Heimpel et al., 1997). Our 16S rDNA sequencing alignment data showed variability that was up to $78.21 \%$ between the two insects. The alignment of 16S rRNA genes revealed differences including substitutions at a higher level. Of course 16S rDNA sequencing has played a pivotal role in the accurate identification and discriminate the genus or species level (Aruggoda, et al., 2010). Although, the percentage of similarity that outcomes from either RAPD-PCR or from 16S rDNA sequencing infer phylogenetic relationships between the two insects, but this percentage could be less than the rate needed to be in the same genus. Whereas, Fry et al., 1991 revealed that the homology of the $16 \mathrm{~S}$ rDNA sequences is less than $98 \%$, then a variety can be considered different and if the homology is less than $93-95 \%$, then a genus can be considered to be different.

In conclusion, 16S rRNA gene sequencing is more powerful than RAPD-PCR for identification of the two insects under study. The similarity revealed differences between the insects arrived to $78.21 \%$ and $86 \%$ by using $16 \mathrm{~S}$ rRNA gene sequencing and RAPD-PCR. The phylogenetic studies provided the evolutionary relationships among different species that reflects their sharing a common ancestor. Moreover, the average genetic differences are high and that make us to reconsider their taxonomy.

\section{REFERENCES}

Aruggoda A. G. B., Shunxiang R. and Baoli Q. (2010). Molecular Phylogeny of Ladybird Beetles (Coccinellidae: Coleoptera) Inferred from Mitochondrial
16S rDNA Sequences. Tropical Agricult. Res., 21(2): 209-217.

Barnay, O., Hommay, G., Gertz, C., Kienlen, J.C., Schubert, G., Marro, J.P., Pizzol, J. and Chavigny, P. (2001). Survey of natural populations of Trichogramma (Hym., Trichogrammatidae) in the vineyards of Alsace (France). Journal of Applied Entomology 125: 469-477.

Chang, S.-C., Hu, N.-T., Hsin, C.-Y. and Sun, C.-N. (2001). Characterization of differences between two Trichogramma wasps by molecular markers. Biological Control 21: 75-78.

DeBach, P.; Rosen, D. (1991). Biological control by natural enemies. Cambridge, UK; Cambridge University Press, 440 pp.

Demichelis, S. and Manino, A. (1998). Electrophoretic detection of parasitism by Dryindae in Typhlobcybinae leafhoppers (Homoptera: Auchenorrhyncha). Canadian Entomologist 130: 407-414.

Fry N. K., Warwick S., Saunders N. A. and Embley T. M. (1991). The use of $16 \mathrm{~S}$ ribosomal RNA analyses to investigate the phylogeny of the family Legionellaceae. J. Gen. Microbiol. 137:1215-1222.

Fuchs H., Gross R., Stein H. and Rottamann O., (1998). Application of molecular markers for the differentiation of bream (Abramis bramaL.) populations from the rivers Main and Danube, J Appl Ichthyol, 14(1-2): 49-55.

Galal F. H. (2009). Comparison of RAPD and PCR-RFLP markers for classification and taxonomic studies of insects Egypt. Acad. J. biolog. Sci., 2 (2): 187-195.

Hebert P. D. N., Cywinska A., Ball S. L., and DeWaard J. R. (2003). Biological identifications through DNA barcodes. Proc. R. Soc. B 270:313-321.

Heimpel G. E., Antolin M. F., Franqui R. A. and Strand M. R. (1997). Reproductive isolation and genetic variation between two "strains" of Bracon hebetor (Hymenoptera: Braconidae). Biol. Control. 9: 149-156.

Jaccard, P. (1908). Nouvelles recherches sur la distribution florale. Bull. Soc. Vaud. Sci. Nat. 44:223-270. 
Jain S. K., Neekhra B., Pandey D. and Jain K. (2010). RAPD marker system in insect study: A review. Indian Journal of Biotechnology 9: 7-12.

Kimani-Njogu, S.K., Overholt, W.A., Woolley, J.B. and Omwega, C.O. (1998). Electrophoretic and phylogenetic analyses of selected allopatric populations of the Cotesia flavipes complex (Hymenoptera: Braconidae), parasitoids of cereal stem borers. Biochemical Systematics and Ecology 26:285-296.

Landry, B.S., Dextraze, L. and Boivin, G. (1993).Random amplified polymorphic DNA markers for DNA fingerprinting and genetic variability of minute parasitic wasp species (Hymenoptera: Mymaridae and Trichogrammatidae) used in biological control programs of phytophagous insects. Genome. Jun; 36(3):580- 587.

Mulcahy, D.L., M. Cresti, S. Sansavini, G.C. Douglas, H.F. Linskens, G.B. Mulcahy, R. Vighani, and M. Pancaldi. (1993). The use of random amplified polymorphic DNAs to fingerprint apple genotypes. Scientia Hort. 54: 89-96.

Pinto, J.D. 1998. Systematics of the North American species of Trichogramma (Hymenoptera: Trichogrammatidae). Mem. Entomol. Soc. Wash. Washington, Allen Press Inc., 22-287p.
Pinto, J.D., Platner, G.R. and Sassaman, C.A. (1993). Electrophoretic study of two closely related species of North American Trichogramma: T. pretiosum and T. deion (Hymenoptera: Trichogrammatidae). Annals of the Entomological Society of America 86: 702-709.

Pungerl, N.B. (1986). Morphometric and electrophoretic study of Aphidius species (Hymenoptera: Aphidiidae) reared from a variety of aphid hosts. Systematic Entomology 11:327-354.

Shouche Y. S. and Patole M. S. (2000). Sequence analysis of mitochondrial $16 \mathrm{~S}$ ribosomal RNA gene fragment from seven mosquito species. J Biosci. 25(4):361-366.

Stouthamer, R., Hu, J., van Kan, F.J.P.M., Platner, G.R. and Pinto, J.D. (1999). The utility of internally transcribed spacer 2 DNA sequences of the nuclear ribosomal gene for distinguishing sibling species of Trichogramma. BioControl 43: 421-440.

Tamura, K., Dudley, J., Nei, M., and Kumar, S. (2007). MEGA4: Molecular Evolutionary Genetics Analysis (MEGA) software version 4.0. Mol Biol Evol 24:1596-1599.

Wolf FC and Rijn JPV (1993). Rapid detection of genetic variability in Chrysanthemum (Dendrantema grandiflora Tzvelev) using random primers. Heredity 71:335-341. 